\title{
Analysis of Factors Influencing Communication and energy Consumption in Wireless Sensor Networks
}

\author{
Zlatan Ganev
}

Technical University of Varna, Department of Electrical Engineering, Studentska 1 str., Varna, Bulgaria

\begin{abstract}
The analysis and experiments presented in this paper are connected with propagation of signals between sensor nodes located in open area. The main purpose is to show some factors that affect the accuracy and reliability of the received signal strength (RSS) measurement as well as the determination of The Path Losses (PL), The Path Loss constant (n) and The Standard deviation $(\sigma)$. The main factors considered here are: position and antenna orientation of sensor nodes and the distance between them.
\end{abstract}

Keywords - model; network; outdoor; propagation; sensor; wireless.

\section{Introduction}

This article presents various cases of transmitting data between wireless sensor nodes located in open areas. In the experiments performed, the received signal strength (RSS) is measured. Then, through calculations, the following values were found:

1) PL - Path Loss.

2) n - Path Loss constant.

3) $\sigma$-Standard deviation.

4) $\operatorname{Pr}(\mathrm{d})$ - Received Power as a function of distance.

DOI: $10.18421 /$ TEM92-04

https://doi.org/10.18421/TEM92-04

Corresponding author: Zlatan Kolev Ganev, Technical University of Varna, Department of Electrical

Engineering, Varna, Bulgaria.

Email: zganev@gmail.com

Received: 20 February 2020.

Revised: 09 April 2020.

Accepted: 17 April 2020.

Published: 27 May 2020.

(cc)BY-Nc-ND (C) 2020 Zlatan Kolev Ganev; published by UIKTEN. This work is licensed under the Creative Commons Attribution-NonCommercial-NoDerivs 3.0 License.

The article is published with Open Access at www.temjournal.com
5) $\operatorname{Pr}[\operatorname{Pr}(\mathrm{d})>\gamma]$ - The probability of received power of the signal to be greater than the set level (threshold) $\gamma[\mathrm{dBm}]$.

6) $\mathrm{U}(\gamma)$ - Percentage prediction of whether the received power inside the area with a given radius (d) will be greater than a given threshold $\gamma$ $[\mathrm{dBm}]$.

For more accurate representation of PL, the Pathloss Shadowing Model - PLSM (also known as Lognormal Shadowing Model is used [11], [12], [13].

This propagation model is very useful because it determines the transmitter coverage area and propagation losses [9], [10]. We can accurately define the communication radius between nodes at a given specific power and transmission frequency. Furthermore, not only we can calculate the transmission power required, but also the battery life of the sensor nodes (SN).

Using this model, we can determine relatively accurately the energy capacity of a Wireless Sensor Network (WSN) even before it is built.

\section{Model}

The Path-loss Shadowing Model described by the formula is used:

$$
\operatorname{PL}[\mathrm{dBm}]=\operatorname{PL}\left(\mathrm{d}_{0}\right)+10 \mathrm{nlg}\left(\mathrm{d} / \mathrm{d}_{0}\right)+\mathrm{X}_{\sigma}
$$

This is an empirical model that analytically approximates the measurement results [5], [6], [7].

The strength of the received signal RSS as a function of distance (d) can be represented by [8]:

$$
\mathrm{RSS}[\mathrm{dBm}]=\mathrm{P}_{\mathrm{t}}-\mathrm{PL}(\mathrm{d})
$$

and

$$
\operatorname{RSS}[\mathrm{dBm}]=\mathrm{P}_{\mathrm{t}}-\mathrm{PL}\left(\mathrm{d}_{0}\right)-10 \mathrm{nlg}\left(\mathrm{d} / \mathrm{d}_{0}\right)-\mathrm{X}_{\sigma}
$$

where $\mathrm{d}$ is the transmit-receive distance (T-R), $\mathrm{d}_{0}$ is the reference distance, $\mathrm{Pt}$ is the transmission power 
in $[\mathrm{dBm}], \mathrm{PL}$ is the Path losses in $[\mathrm{dB}], \mathrm{n}$ is the Path Loss constant. $\mathrm{X} \sigma$ is a random variable with Gaussian distribution with zero mean and standard deviation $\sigma[\mathrm{dB}][2]$. X $\sigma$ has an approximate value of 8 to $10 \mathrm{~dB}(9 \mathrm{~dB}$ is taken into account for calculations here) and can be found by the formula [3]:

$$
\mathrm{X}_{\sigma}(\mathrm{RSS})=\frac{1}{\sigma \sqrt{2 \pi}} \exp \left(\frac{-(\mathrm{RSS}-\mu)^{2}}{2 \sigma^{2}}\right)
$$

where $\mu$ is the average value of RSS (assumed to be zero here) .

\section{Finding $n$ and $\sigma$ :}

The least squares method: MMSE (minimum mean square error) is used to find the Path Loss constant $(n)$ and standard deviation $(\sigma)$.

I take into account the fact that the reference distance for the propagation of signals is $\mathrm{d}_{0}=1 \mathrm{~m}$ and that the losses for this distance in the particular case PL(d0) are known.

The sum of the quadratic error to be minimized is [4]:

$\mathrm{S}(\mathrm{n})=\sum_{\mathrm{k}=0}^{\mathrm{N}}\left(\mathrm{p}_{\mathrm{k}}-\mathrm{p}_{\mathrm{k}}^{\prime}\right)^{2}$

where by $p_{k}$ ' I denote the received RSS power calculated by the equation,

$$
\mathrm{p}_{\mathrm{k}}{ }^{\prime}=\mathrm{RSS}_{\mathrm{k}}=\mathrm{RSS}_{\mathrm{k}}\left(\mathrm{d}_{0}\right)-10 \mathrm{nlg}\left(\mathrm{d}_{\mathrm{k}} / \mathrm{d}_{0}\right)
$$

and with $\mathrm{p}_{\mathrm{k}}$, the power received from the measurements. Here $\mathrm{k}=1,2, \ldots, \mathrm{N}$, and $\mathrm{N}$ is the total number of measurements taken. follows:

The minimum requirement is expressed as

$$
\frac{\mathrm{dS}}{\mathrm{dn}}=0
$$

whence we mathematically determine the Path Loss constant (n).

The standard deviation $(\sigma)[\mathrm{dB}]$ is given by the formula:

$$
\sigma[\mathrm{dB}]=\sqrt{\mathrm{S}(\mathrm{n}) / \mathrm{N}}
$$

It is found that as the number of measurements $\mathrm{N}$ increases, the parameter $(\sigma)$ decreases.

\section{Calculation of the received power at a certain distance:}

To calculate the received power $\operatorname{Pr}(\mathrm{Pr}=\mathrm{RSS})$ at a specified distance (d) from the transmitter, having found $(n)$ and $(\sigma)$, we can use the equation [8]:

$$
\mathrm{P}_{\mathrm{r}}(\mathrm{d})=\operatorname{RSS}(\mathrm{d})=\operatorname{RSS}\left(\mathrm{d}_{0}\right)-10 \operatorname{nlg}\left(\mathrm{d} / \mathrm{d}_{0}\right)+\mathrm{X}_{\sigma}
$$

When we know the transmission power $\mathrm{Pt}$, we can also use equation (3) to calculate the received power $\operatorname{Pr}(\mathrm{d})$.

Calculation of the probability that the received signal Pr is greater than the set threshold $\gamma$ :

The following equation:

$$
\operatorname{Pr}\left[\mathrm{P}_{\mathrm{r}}(\mathrm{d})>\gamma\right]=\mathrm{Q}\left(\frac{\gamma-\operatorname{Pr}(\mathrm{d})}{\sigma}\right)
$$

is obtained for this probability [4], in which

$$
\mathrm{Q}(\mathrm{z})=0.5[1+\operatorname{erf}(z / \sqrt{2})]
$$

Percentage prediction for an area with a given radius $d$, that determines whether the received power inside the area will be greater than a given threshold $\gamma$ :

The probability that the signal level obtained is greater than $\gamma[\mathrm{dBm}]$ is represented according to the following equation [4]:

$\mathrm{U}(\gamma)=0.5\left\{1+\exp \left(1 / \mathrm{b}^{2}\right)[1-\operatorname{erf}(1 / \mathrm{b})]\right\}$

where parameter (b) is defined by equation

$$
\mathrm{b}=(10 \mathrm{nlge}) /(\sigma \sqrt{2})
$$

\section{Experimental Setup}

The experiments are made in the area of the University of Patra - Greece. The sensor nodes (Tmote Sky and TelosB), as well as the whole measurement equipment, are supplied by the Laboratory - APEL (Applied Electronics Laboratory) at the Electrical and Computer Engineering Department. 


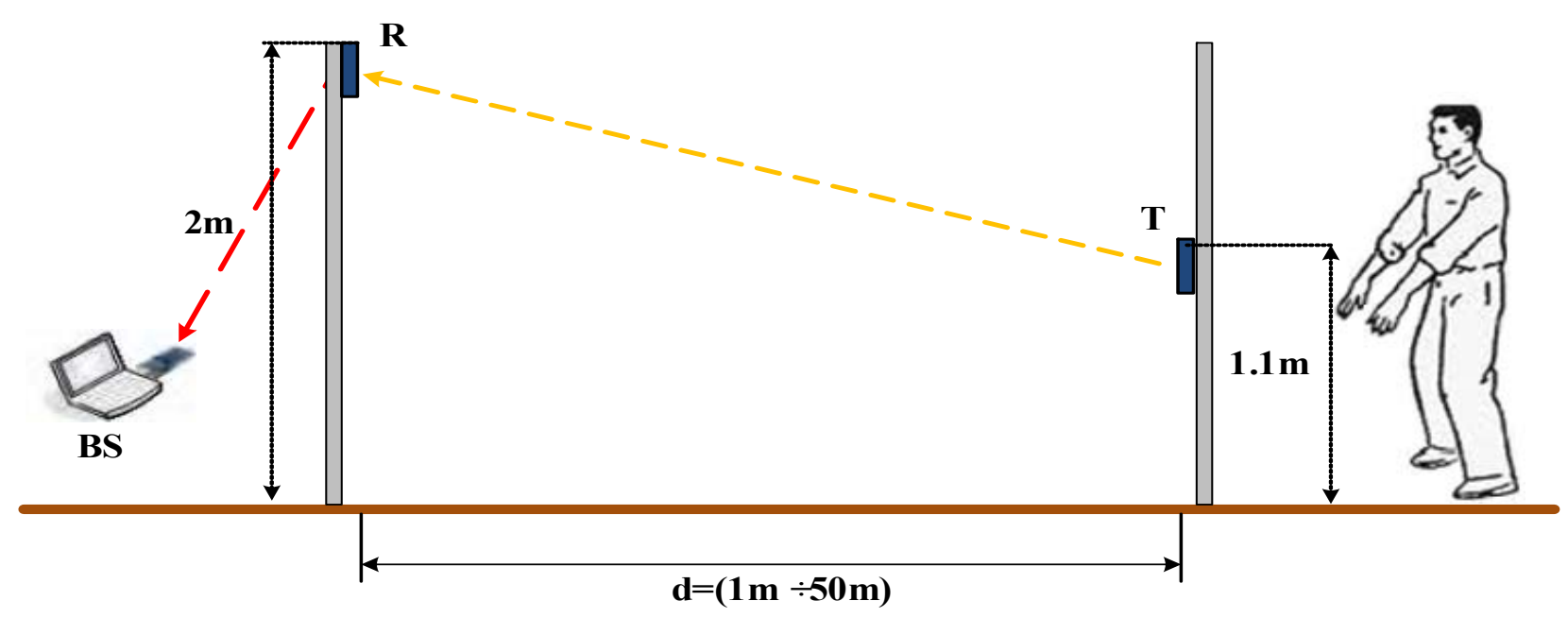

Figure 1. Experimental setup

The scheme of the experimental setup is shown in Figure 1. The sensor nodes are mounted on two twometer tripods. The first tripod (from right to left in the figure) is fitted with a transmitter (T), located at a height of $1.1 \mathrm{~m}$ from the ground.

\section{Experiments and Results}

Every $150 \mathrm{msec}$ it transmits a packet of information to the receiving node $(\mathrm{R})$ located on the second tripod at a height of $2 \mathrm{~m}$ from the ground. Each packet contains 21 bytes, and for each measurement 100 packets are transmitted from $\mathrm{T}$ to $\mathrm{R}[1]$.

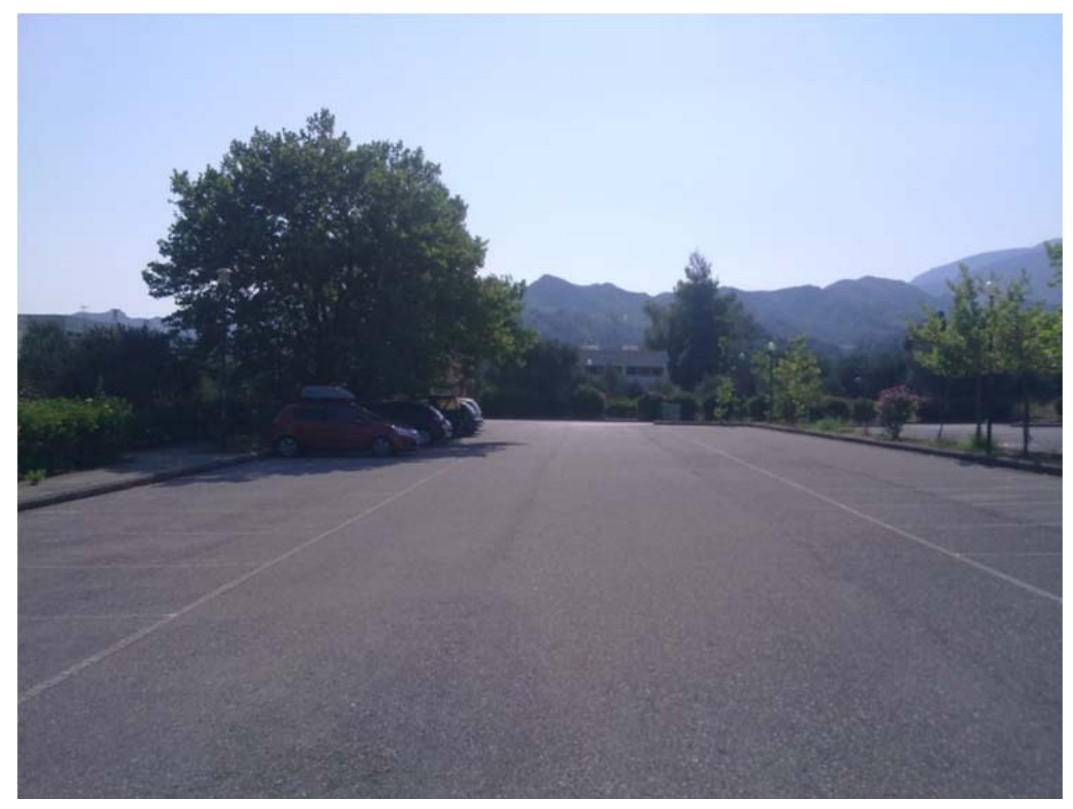

Figure 2. Open-air parking

RSS measurements were made in an open-air parking area (Figure 2) in line-of-sight (LoS) transmission between nodes. The main objective of the experiment is to calculate $(n)$ and $(\sigma)$ by the obtained results, and thus to make an analysis of the influence of environmental factors on the propagation of signals at different locations (horizontal and vertical) of the nodes in relation to each other in the particular environment.
Received information from $(\mathrm{R})$ is transmitted to the Base Station (BS), which is connected via USB to a laptop where it is processed and RSSI (Receive Signal Strenght Indicator) is extracted from it. Then, through additional calculations, the received RSS power is obtained using the known formula from the

Manual:

RSS $[\mathrm{dBm}]=$ RSSI_VAL + RSSI_OFFSET 
In (14), RSSI_OFFSET is the empirically found value of RSSI from the experiment.

For this purpose, a special software program running on the TinyOS operating system was used, as shown in Fig.3.
According to the CC2420 specification, RSS_VAL is $-45 \mathrm{dBm}$. Therefore, if we extract the RSSI Number -20 (which we already mentioned is RSSI_OFFSET) from the program register, then the strength of the received signal according to (14) will be $\mathrm{RSS}=-20+(-45)=-65 \mathrm{dBm}$.

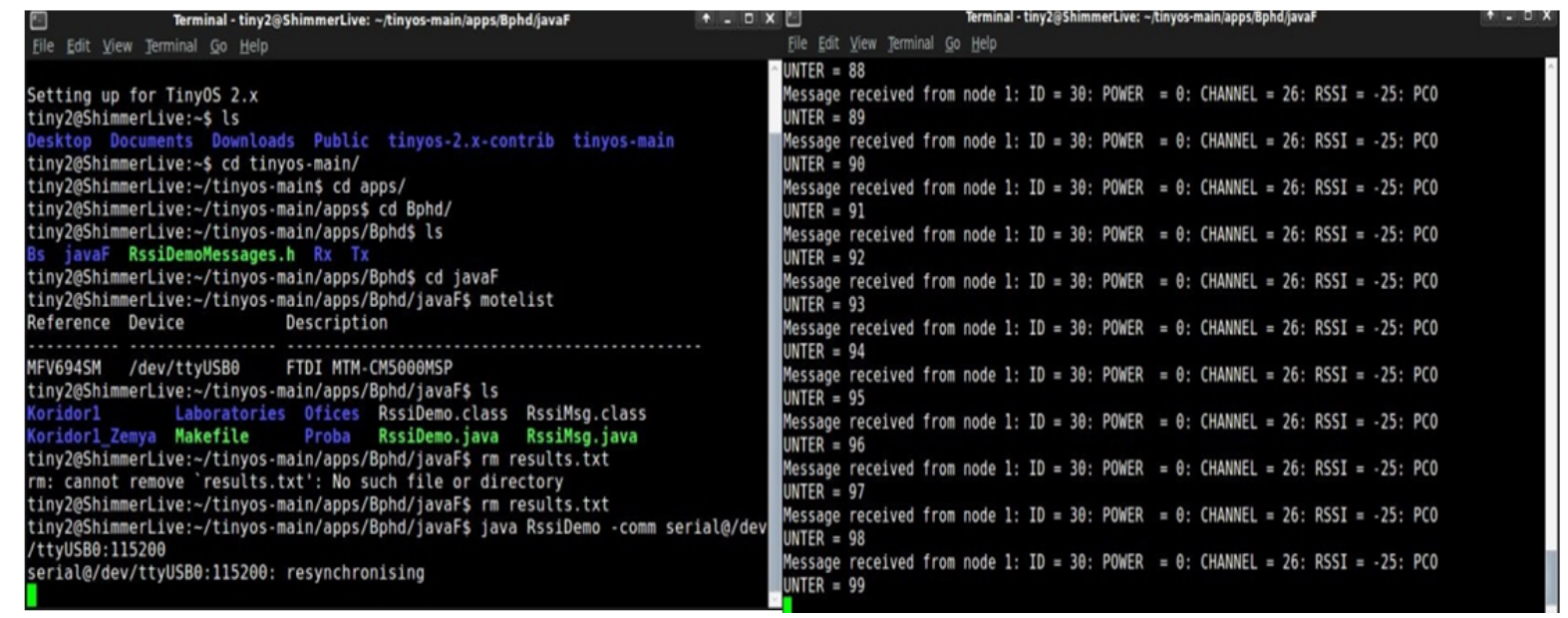

Figure 3. Program for finding RSSI_OFFSET

Measurements were made at two positions of the sensor nodes in relation to each other:

a) Horizontally $(\mathrm{H})$ - with antennas pointing up and power batteries - down;

and

b) vertically (V) - with antennas facing each other.
The layout of the experimental set-up is the same as it is shown in Fig. 1, but in one of the measurements the nodes are horizontally and in the other - vertically oriented to each other (Fig.4). The transmission frequency is $2,480 \mathrm{GHz}$ and the transmission power is $\mathrm{Pt}=0 \mathrm{dBm}$. The information packets are transmitted sequentially from $T$ to $R$ and from there to BS connected via USB to the Laptop.
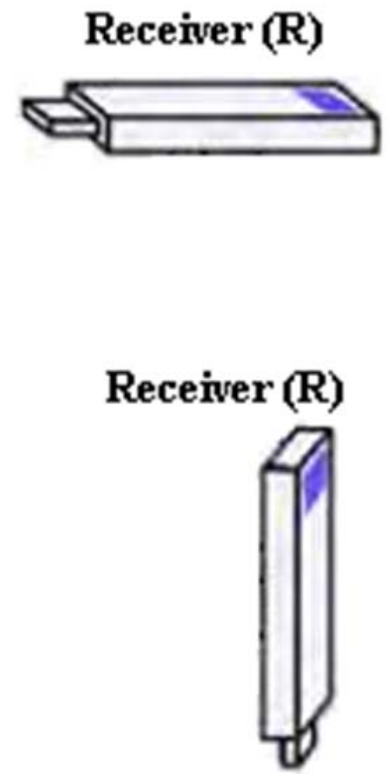

\section{Transmitter ( $\mathrm{T}$ )}

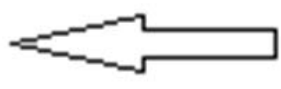

a)
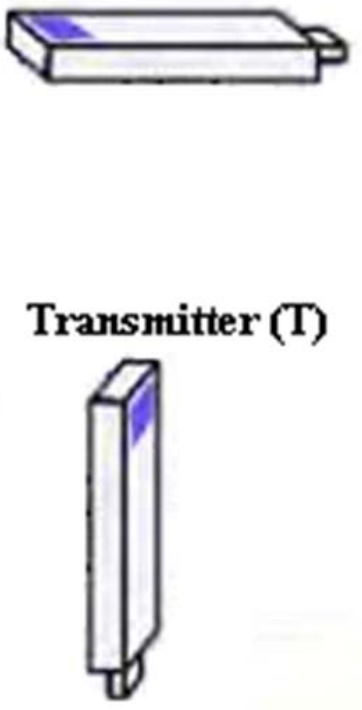

\section{b)}

Figure 4. a) Horizontal (H) and b) Vertical (V) positioning of sensor nodes 
The calculations of RSS and PL in a) and b) case follow the same sequence as described in details above. The results from calculations are presented in Table 1, shown graphically in Figure 5.

Table 1. Results from the experiment, $P_{t}=0 \mathrm{dBm} ; f=2.480 \mathrm{GHz} ; \mathrm{d}=1-50 \mathrm{~m}$

\begin{tabular}{|c|c|c|c|c|c|c|}
\hline$\underset{\Xi}{\Xi}$ & 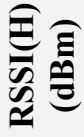 & 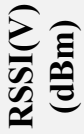 & 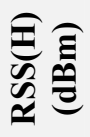 & 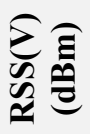 & 胥 & $\sum_{\underline{a}}$ \\
\hline 1 & 5 & 15 & -40 & -30 & 40 & 30 \\
\hline 2 & -13 & 5 & -58 & -40 & 58 & 40 \\
\hline 3 & -15 & -17 & -60 & -62 & 60 & 62 \\
\hline 4 & -15 & -8 & -60 & -53 & 60 & 53 \\
\hline 5 & -8 & -16 & -53 & -61 & 53 & 61 \\
\hline 6 & -15 & -27 & -60 & -72 & 60 & 72 \\
\hline 7 & -25 & -14 & -70 & -59 & 70 & 59 \\
\hline 8 & -23 & -17 & -68 & -62 & 68 & 62 \\
\hline 9 & -24 & -27 & -69 & -72 & 69 & 72 \\
\hline 10 & -23 & -15 & -68 & -60 & 68 & 60 \\
\hline 11 & -16 & -16 & -61 & -61 & 61 & 61 \\
\hline 12 & -24 & -43 & -69 & -88 & 69 & 88 \\
\hline 13 & -26 & -19 & -71 & -64 & 71 & 64 \\
\hline 14 & -35 & -14 & -80 & -59 & 80 & 59 \\
\hline 15 & -23 & -15 & -68 & -60 & 68 & 60 \\
\hline 16 & -18 & -16 & -63 & -61 & 63 & 61 \\
\hline
\end{tabular}

a) Horizontal position of $\mathrm{SN}-\mathrm{n}_{\mathrm{H}}=2.2053 ; \sigma_{\mathrm{H}}=6.011$

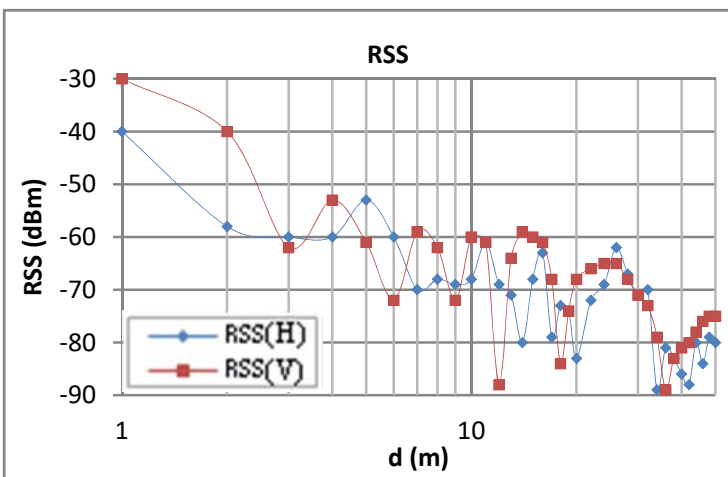

\begin{tabular}{|l|l|l|l|l|l|l|}
\hline 17 & -34 & -23 & -79 & -68 & 79 & 68 \\
\hline 18 & -28 & -39 & -73 & -84 & 73 & 84 \\
\hline 19 & -29 & -29 & -74 & -74 & 74 & 74 \\
\hline 20 & -38 & -23 & -83 & -68 & 83 & 68 \\
\hline 22 & -27 & -21 & -72 & -66 & 72 & 66 \\
\hline 24 & -24 & -20 & -69 & -65 & 69 & 65 \\
\hline 26 & -17 & -20 & -62 & -65 & 62 & 65 \\
\hline 28 & -22 & -23 & -67 & -68 & 67 & 68 \\
\hline 30 & -26 & -26 & -71 & -71 & 71 & 71 \\
\hline 32 & -25 & -28 & -70 & -73 & 70 & 73 \\
\hline 34 & -44 & -34 & -89 & -79 & 89 & 79 \\
\hline 36 & -36 & -44 & -81 & -89 & 81 & 89 \\
\hline 38 & -38 & -38 & -83 & -83 & 83 & 83 \\
\hline 40 & -41 & -36 & -86 & -81 & 86 & 81 \\
\hline 42 & -43 & -35 & -88 & -80 & 88 & 80 \\
\hline 44 & -35 & -33 & -80 & -78 & 80 & 78 \\
\hline 46 & -39 & -31 & -84 & -76 & 84 & 76 \\
\hline 48 & -34 & -30 & -79 & -75 & 79 & 75 \\
\hline 50 & -35 & -30 & -80 & -75 & 80 & 75 \\
\hline
\end{tabular}

b) Vertical position of $\mathrm{SN}-\mathrm{n}_{\mathrm{V}}=3.1111 ; \sigma_{\mathrm{V}}=8.3022$

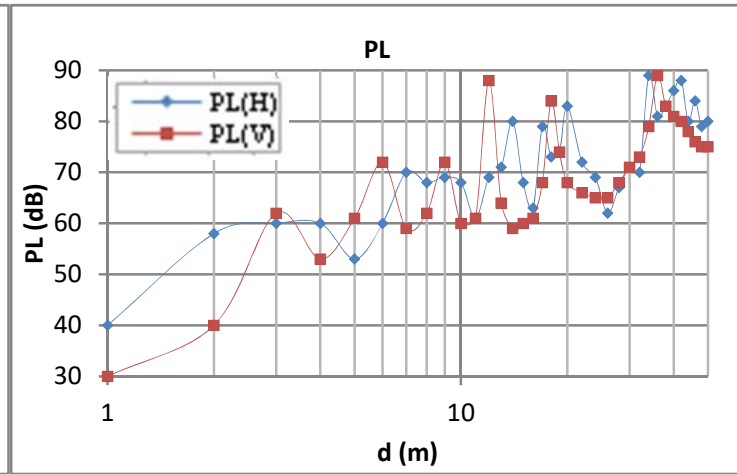

Figure 5. Graphics of RSS and PL with Horizontal and Vertical orientation of SN

Having found the Path Loss constant (n) and the standard deviation $(\sigma)$ for the two cases in a) horizontal and b) vertical positioning, I can now calculate a few more things:

- the received power $\operatorname{Pr}(\mathrm{d})$ at a specified distance $\mathrm{d}$ $=32 \mathrm{~m}$;

- the probability that the received signal $\operatorname{Pr}[\operatorname{Pr}(\mathrm{d})>$ $\gamma]$ is greater than the set threshold $\gamma=-77$ $[\mathrm{dBm}]$;

- the percentage prediction $\mathrm{U}(\gamma)$ for an area with a given radius $\mathrm{d}$, that determines whether the received power inside the area will be higher than the set threshold $\gamma=-77[\mathrm{dBm}]$.

\section{a) Horizontal node positioning.}

a1) Calculation of the received power $\operatorname{Pr}(d)$.

From (9) for $\mathrm{d}=32 \mathrm{~m}$ it follows:

$\mathrm{P}_{\mathrm{r}}(\mathrm{d}=32 \mathrm{~m})=-40 \mathrm{dBm}-10(2.2053) \lg (32 / 1)+9 \mathrm{~dB}$ $=-64.2 \mathrm{dBm}$. 
a2) Calculation of the probability that the received signal $\operatorname{Pr}\left[P_{r}(d)>\gamma\right]$ is greater than the set threshold $\gamma[\mathrm{dBm}]$.

I set the threshold to be $\gamma=-77 \mathrm{dBm}$. Then from (10) and (11) it follows:

$\operatorname{Pr}\left[\mathrm{P}_{\mathrm{r}}(\mathrm{d})>\gamma\right]=\mathrm{Q}(-2.13)=0.0166=1.66 \%$

a3) Percentage prediction for an area with a given radius $d$, that determines whether the received power inside the area will be greater than the given threshold $\gamma[\mathrm{dBm}]$.

The probability is represented by equation (12) and (13) and after a substitution the result is:

$$
\mathrm{U}(-77 \mathrm{dBm})=33.5 \%
$$

\section{b) Vertical node positioning.}

\section{b1) Calculation of the received power $\operatorname{Pr}(d)$.}

From (9) for $\mathrm{d}=32 \mathrm{~m}$ it follows:

$\mathrm{P}_{\mathrm{r}}(\mathrm{d}=32 \mathrm{~m})=-30 \mathrm{dBm}-10(3.1111) \lg (32 / 1)+9 \mathrm{~dB}$ $=-67.82 \mathrm{dBm}$

b2) Calculation of the probability that the received signal $\operatorname{Pr}[\operatorname{Pr}(d)>\gamma]$ is greater than the threshold $\gamma$ [dBm.].

The threshold is again $\gamma=-77 \mathrm{dBm}$ and from (10) and (11) it follows:

$\operatorname{Pr}\left[\mathrm{P}_{\mathrm{r}}(\mathrm{d})>\gamma\right]=\mathrm{Q}(-1.106)=0.11=11 \%$

b3) Percentage prediction for an area with a given radius $d$, that determines whether the received power inside the area will be higher than the given threshold $\gamma[\mathrm{dBm}]$.

The probability is represented by equation (12) and (13) and after a substitution the result is:

$$
\mathrm{U}(-77 \mathrm{dBm})=39.33 \% \text {. }
$$

\section{Conclusion}

The experiments presented in this article aim to show some factors that affect the accuracy and reliability of the received signal strength (RSS) measurements as well as the determination of losses (PL), Path Loss constant (n) and standard deviation $(\sigma)$. The factors considered are: distance between transmitter and receiver (d) and antenna position and orientation of sensor nodes. In the experiments performed, the transmission frequency (f), transmission power Pt and the environment did not change.

To determine the losses, one statistical distribution model was used: Path-Loss Shadowing Model (PLSM). It is also known in the literature as Lognormal Shadowing Model (LNSM). This model is simple and realistic, because it takes into account the losses of shading. By determining the losses at the reference point PL (d0), as well as the Path Loss constant (n) and the standart deviation $(\sigma)$, the PLSM calculated the received power at a given distance.

The experiments were made with sensor nodes Tmote Sky and TelosB in open spaces (car parking) in the area of the University of Patras, Greece.

The results and conclusions obtained from these experiments are summarized as follows:

RSS measurements were made in direct line of sight $(\mathrm{LoS})$ between sensor nodes at two positions:

a) horizontally and b) vertically oriented.

From the results obtained, it was found that, when two different positions of the nodes relative to the ground (horizontal and vertical) are used with the same parameters set in both cases (environment, height of SN, frequency, distance and transmission power), there is a difference in the values obtained for RSS, PL and (n). It can be seen that in vertical positioning the losses are generally smaller (Table 1). This may be mainly due to the different antenna pattern in the different planes. This should be taken into account when constructing a wireless sensor network. Another reason for this difference can be found in the fact that the scattering environment is less inhomogeneous in the vertical plane than in the horizontal plane.

Furthermore, the following additional calculations were made in this experiment: Calculation of the received power $\operatorname{Pr}(\mathrm{d})$ at a given distance $\mathrm{d}=32 \mathrm{~m}$; Calculation of the probability $\operatorname{Pr}[\operatorname{Pr}(\mathrm{d})>\gamma]$ that the received signal is greater than a threshold $\gamma=-77$ $\mathrm{dBm}$; the percentage prediction $\mathrm{U}(\gamma)$ for an area with a given radius $d$, showing whether the received power inside that area will be higher than the set threshold $\gamma=-77[\mathrm{dBm}]$. It can be seen that when we have the vertical positioning of the sensor nodes, $\operatorname{Pr}[\operatorname{Pr}(\mathrm{d})>\gamma]$ and $\mathrm{U}(\gamma)$ are bigger. This, in turn, makes communication in this case better and more reliable.

Based on the results obtained, the parameters of a WSN can be calculated and its efficiency can be predicted.

A multi-hop model can also be applied further on to reduce losses in communication between sensor nodes and thus to optimize the wireless sensor network. 


\section{References}

[1]. Ganev.Z.,(2016).Optimized energy model of wireless sensor networks, $\mathrm{PhD}$ Theses, Department of Electrical engineering, Technical University of Varna, Bulgaria.

[2]. Stoyanova, T., Kerasiotis, F., Prayati, A., \& Papadopoulos, G. (2009). Evaluation of impact factors on RSS accuracy for localization and tracking applications in sensor networks. Telecommunication Systems, 42(3-4), 235.

[3]. Ganev Z. , Savov S.,(2015). Propagation of electromagnetic waves between wireless sensor nodes in one corridor, ELMA 2015, Conference Proceedings, pp.270-273, 1-3 October, Varna, Bulgaria.

[4]. Rappaport, T. S. (2002). Wireless Communications-Principles and Practice, (The Book End). Microwave Journal, 45(12), 128-129.

[5]. Maccartney, G. R., Rappaport, T. S., Sun, S., \& Deng, S. (2015). Indoor office wideband millimeter-wave propagation measurements and channel models at 28 and $73 \mathrm{GHz}$ for ultra-dense $5 \mathrm{G}$ wireless networks. IEEE access, 3, 2388-2424.

[6]. Karl, H., \& Willig, A. (2007). Protocols and architectures for wireless sensor networks. John Wiley \& Sons.
[7]. Rabaey, J. M., Ammer, M. J., Da Silva, J. L., Patel, D., \& Roundy, S. (2000). PicoRadio supports ad hoc ultra-low power wireless networking. Computer, 33(7), 42-48.

[8]. Stoyanova, T. (2011). RF signal modeling and deployment strategy targeting outdoor RSS-based localization and tracking applications in wireless sensor network (Doctoral dissertation). PhD Theses, Faculty of Electrical and Computer Engineering, Universyty of Patras, Greece

[9]. Oestges, C. (2005). Propagation Modeling for Wireless Sensor Networks. Report, Catholique Universite de Louvain.

[10]. Molisch, A. F. (2012). Wireless communications (Vol. 34). John Wiley \& Sons., $\left(2^{\text {nd }}\right.$ ed.), Wiley, 2005.

[11].Janvier, D. (2006). Propagation Models for Wireless Sensor Communications. Report, Catholique Universite de Louvain.

[12]. Hossain, A., Biswas, P. K., \& Chakrabarti, S. (2008, December). Sensing models and its impact on network coverage in wireless sensor network. In 2008 IEEE Region 10 and the Third international Conference on Industrial and Information Systems (pp. 1-5). IEEE.

[13].Joseph, W., Roelens, L., \& Martens, L. (2006, July). Path loss model for wireless applications at 3500 MHz. In 2006 IEEE Antennas and Propagation Society International Symposium (pp. 4751-4754). IEEE. 